This item was submitted to Loughborough's Research Repository by the author.

Items in Figshare are protected by copyright, with all rights reserved, unless otherwise indicated.

\title{
The social context as a determinant of teacher motivational strategies in physical education
}

PLEASE CITE THE PUBLISHED VERSION

http://dx.doi.org/10.1016/j.psychsport.2008.09.002

PUBLISHER

(C) Elsevier Ltd

VERSION

AM (Accepted Manuscript)

LICENCE

CC BY-NC-ND 4.0

\section{REPOSITORY RECORD}

Taylor, lan M., Nikos Ntoumanis, and Brett M. Smith. 2019. "The Social Context as a Determinant of Teacher Motivational Strategies in Physical Education”. figshare. https://hdl.handle.net/2134/15372. 
This item was submitted to Loughborough's Institutional Repository (https://dspace.lboro.ac.uk/) by the author and is made available under the following Creative Commons Licence conditions.

\section{creative
commons}

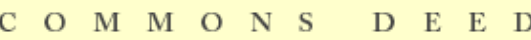

Attribution-NonCommercial-NoDerivs 2.5

You are free:

- to copy, distribute, display, and perform the work

Under the following conditions:

Attribution. You must attribute the work in the manner specified b the author or licensor.

Noncommercial. You may not use this work for commercial purposes.

No Derivative Works. You may not alter, transform, or build upon this work.

- For any reuse or distribution, you must make clear to others the license terms of this work.

- Any of these conditions can be waived if you get permission from the copyright holder.

Your fair use and other rights are in no way affected by the above.

This is a human-readable summary of the Leqal Code (the full license).

\section{Disclaimer 만}

For the full text of this licence, please go to: http://creativecommons.org/licenses/by-nc-nd/2.5/ 
THE SOCIAL CONTEXT AS

The Social Context as a Determinant of Teacher Motivational Strategies in Physical Education 


\begin{abstract}
The purpose of the study was to provide an in-depth analysis of how the Physical Education (PE) teaching context influences teachers’ motivational strategies towards students. Using Self-determination theory (Deci \& Ryan, 2000) as a guiding framework, semi-structured interviews of $22 \mathrm{PE}$ teachers were examined using categorical content analysis. The teachers perceived that an emphasis on student assessment and the time constraints associated with PE lessons often compelled them to use teaching strategies which conflicted with their beliefs about the most appropriate ways to motivate students. The teachers' own performance evaluations and pressure to conform to other teachers' methods also influenced the teachers' motivational strategies, but these influences were often congruent with their teaching beliefs. Additionally, the teachers discussed how perceived cultural norms associated with the teacher-student relationship impacted upon their chosen motivational strategies. These cultural norms were reported by different teachers as either in line, or in conflict with their teaching beliefs. Finally, the influence of the teachers' perceptions of their students helped produce strategies that were congruent with their beliefs, but often different to empirically suggested strategies. Consequently, it is important that teacher beliefs are targeted in education programs and that the teaching context aid in facilitating adaptive motivational strategies.
\end{abstract}

Keywords: autonomy, competence, relatedness, categorical content analysis, teaching context. 
The Social Context as a Determinant of Teacher Motivational Strategies in Physical

\section{Education}

An important context that may have great potential to promote youth physical activity is the Physical Education (PE) class since, unlike competitive sport; it ostensibly strives to encompass virtually all children (Cavill, Biddle, \& Sallis, 2001). In order to promote sensible and healthy physical activity through PE it is important to consider how motivating PE classes are for students, as motivation has been empirically linked to important consequences in $\mathrm{PE}$, such as the intention to be physically active and leisure time physical activity behavior (e.g., Hagger, Chatzisarantis, Culverhouse, \& Biddle, 2003). Using various theoretical frameworks, extensive discussion has occurred concerning how teachers can influence student motivation in PE. For example, research using self-determination theory (SDT; Deci \& Ryan, 2000) indicates that the degree to which PE teachers support students’ psychological needs for autonomy, competence and relatedness is positively associated to students’ adaptive self-determined motivation. (e.g., Taylor \& Ntoumanis, 2007).

Using SDT as a guiding framework, the purpose of this article was to explore how PE teachers' perceptions of the teaching context influence their attempts to motivate students in their PE classes. Regardless of the research evidence indicating which teaching strategies may be adaptive; teachers may not always utilize them in their teaching (Reeve, 2002). For example, first year elementary teachers were observed to utilize rewards as their primary motivational strategy (Newby, 1991), despite the effectiveness of this strategy being questioned (e.g., Deci, Ryan \& Koestner, 2001). Given this information, an exploration into why this discrepancy between empirical suggestions and actual teaching practice sometimes occurs seems worthy.

Within the SDT framework, the social context has previously been shown to be related to teachers' use of motivational strategies. Pelletier, Seguin-Levesque and Legault 
(2002) reported that various pressurizing constraints at work were negatively related to the degree of autonomy support teachers provided (e.g., providing students with choice and a meaningful rationale). Nonetheless, some constraints may be more pertinent to teachers than others. For example, the teachers quantitatively reported very little pressure to conform to colleagues' teaching methods, but a high degree of pressure to complete the curriculum. In view of this, further, in-depth investigation of the different aspects of the teaching context is required.

Other studies have shown that the more teachers feel that they are responsible for student performance standards, the more controlling they are towards students and less effective they are in their teaching (Deci, Spiegel, Ryan, Koestner, \& Kauffman, 1982; Flink, Boggiano, \& Barrett, 1990). However, in these studies, the teaching context has been artificially created by the experimenters, often in laboratory environments. Hence, studies that shift the context from the laboratory to the everyday contextual events that teachers' face are required to explore whether the processes found in experimental designs occur in teachers' lived experiences. If these processes do occur, what do the teachers, as living beings, feel about them?

As well as pressures that generally stem from higher authorities in the school system (e.g., responsibility for student performance), studies including Pelletier et al. (2002) have proposed that teachers are influenced by their perception of students' motivation and behavior. For instance, the degree to which PE teachers' perceive their students to be selfdetermined towards PE has been shown to be positively associated with autonomy supportive, emotionally involved and structured teaching environments (Taylor, Ntoumanis, \& Standage, 2008). Similarly, when teachers have positive achievement expectations of their students, adaptive teaching environments may also occur (e.g., Harris \& Rosenthal, 1985). 
Building on this, the present study wished to explore whether teachers are aware of these potential biases towards some students.

Much of the research described above has been undertaken in classroom contexts, with PE receiving less attention partly due to the marginality of PE in the national curriculum (Sparkes, Templin, \& Schempp, 1990). However, this peripheral position of PE also means that PE teachers work in a very different occupational environment compared to teachers in “core” subjects. Consequently, any contextual pressures associated with PE may be somewhat different to that of alternative subjects and, therefore, require separate exploration. Moreover, much of the aforementioned, SDT-based research offers a sound foundation for the assessment of determinants of autonomy support, but other methods of motivating students must be considered. Against this background of neglect, the present study attempts to ask two primary research questions. First, do PE teachers perceive the teaching context to influence their attempts to motivate students? Second, if the teaching context does play a role, what do PE teachers think of these influences? This second question is important because PE teachers may be forced to teach in certain ways that are in conflict with their teaching beliefs. If teachers behave in ways that they do not value, this may have negative implications for the teachers’ own motivation and well-being (Deci \& Ryan, 2000).

\section{Methodology \& Methods}

Methodologically speaking, this paper commits to interpretivism, or what has more recently been termed non-foundationalism (see Sparkes, 1992; Smith \& Deemer, 2000; Smith \& Sparkes, in-press a). The methods utilized, such as the sampling plan, interviews, data collection, and analysis, are framed by this paradigm. This should be borne in mind when reading the following methods section and judging our interpretations of the data generated. 
Having gained approval from a university ethics committee, access was gained to the participants by (first author) via purposive and maximum variation sampling based on obtaining a variety of ages, experience, and gender, as well as sampling from schools with a varied average student socio-economic status. These sampling methods are particularly useful for highlighting both uniqueness in the sample and shared patterns across different participants (Patton, 2002).

Data from interviews with thirteen male and nine female PE teachers working in central or southern England will be used to illustrate the PE teachers' accounts. All but one interviewee were of White ethnicity and one teacher was of Australian nationality. Teachers ranged in age from 22 to 56 years and teaching experience ranged from 0 to 33 years. Twenty teachers were employed by co-educational (i.e. mixed-sex) schools, one taught in a boysonly school and one in a girls-only school. Furthermore, 20 worked in state schools and two in private schools. Pseudonyms for each teacher are given throughout in order to assist anonymity.

An interview guide was developed to provide a framework to the interaction while at the same time attempting to remain flexible and sensitive to emergent issues. The intention during interviews, following recommendations by Chase (1995) and Smith and Sparkes (inpress a, b), was to invite the participants to tell their stories rather than simply provide reports. The interviews were semi-structured in nature with the guide acting as a loose collection of related themes as opposed to the detailed set of questions and probes that characterize more formal interview schedules (Patton, 2002).

The themes incorporated in the guide were as follows: "How do you assess students' motivation in lessons?”, “Some teachers have mentioned some types of students are more motivated in PE than others, whilst some have not mentioned this, can you think of any?”, "Do you feel any pressure from any sources when thinking about how you motivate 
students?”, “What do you think motivates students to participate in PE?”, and “Can you give me specific examples when you have used this strategy?”. The interview themes included in the guide were generated with regard to the work of scholars in the field of social, sport and educational psychology in general, and SDT in particular. For example, in relation to SDT, the initial starting point was the work of Deci and Ryan (2000). Their research highlighted a number of key themes pertinent to motivation, such as the support of autonomy. Specifically, SDT hypothesizes that the degree to which the environment supports individuals' autonomy positively influences one’s behaviors towards others (Gagné, 2003). Likewise, contextual factors have also been shown to influence PE teachers' motivational strategies towards students via the degree to which teachers’ psychological needs are satisfied (Taylor et al., 2008). Given these propositions, and because our purpose was in part to explore SDT in relation to teachers lives and visa versa, we based our data collection and analysis on contextual factors that may influence teachers' behaviors towards students because they satisfy/thwart teachers’ psychological needs (e.g., time constraints, pressure to conform to colleagues' methods, responsibility for student standards). The SDT-based psychological needs also influenced our interpretations of the teachers' motivational strategies. In particular, we interpreted the teachers' examples of their behaviors towards students in terms of satisfying or thwarting students’ psychological needs. These themes provided not only an invitation to disclose personal experiences but also served to locate such experiences in relation to previous SDT-based research. Despite this theory-based perspective, one of the strengths of qualitative research is its ability to facilitate the identification of unanticipated phenomena and influences, and generate new theories about the latter. At the same time, we are cautious to claim that that this research is purely inductive (or deductive) in nature. For one, we all interpret research with certain prejudices (Gadamer, 1975) and no matter how hard we try we cannot achieve theory-free observation or knowledge (Smith \& Deemer, 
2000). Likewise, and as noted, we purposely set out to interpret the data generated through the lens of SDT whilst aspiring to be critically reflexive and cognisant of unanticipated phenomena and themes unrelated to SDT, or which might challenge it. Hence, our overall approach may be described as abductive in nature. That is, a dialogue between data and theory was undertaken throughout the research process. Our analytical process was a dialectical movement between everyday meanings and theoretical explanations.

Interviews were arranged with each participant at a location of their choice. At the start of the interview (first author), who conducted all the interviews and was the only person to listen to them and transcribe them in order to ensure confidentiality, provided a brief outline of the study and explained his interest in motivation and teaching. Participants were invited to ask questions about the project prior to signing an informed consent form which included permission to audio tape record each interview, and to use their comments in future publications. The flexible nature of the process and the individual responses of the participants resulted in interviews of differing lengths. On average each interview lasted approximately one hour.

Following the interviews, and mindful of our points raised above regarding the abductive analytical process, (first author) adopted the qualitative posture of 'indwelling' and listened to the tapes several times, making notes and jotting down initial impressions. This reflective posture, according to Maykut and Morehouse (1994), “means to live within ... understanding the person's point of view from an empathetic rather than a sympathetic position” (p.25). This posture was maintained when the interviews were transcribed verbatim and the transcripts read through several times by him in order to further immerse himself in the data.

Next, the transcripts were read through again and subjected to a categorical-content analysis that, according to Lieblich, Tuval-Mashiach and Zilbar (1998), is similar to a 
traditional approach in qualitative content analysis in which "categories of the studied topic are defined, and separate utterances of the text are extracted, classified, and gathered into these categories/groups” (p. 13). During this process, analytical memos were written as preliminary connections were made between theoretical concepts and specific issues emerging from the participant's individual story and how these connected to wider cultural narratives. The analytical memos along with the coding helped shape the analytic process. This form of analysis is intended to examine the thematic similarities and differences between the accounts provided. The strength of this approach lies in its capacity to develop general knowledge about the core themes that make up the content of the accounts collected in interview contexts with a view to identifying narrative segments and categories within it.

In order to develop plausible interpretations, throughout the categorical-content analysis, (first author) presented his emerging findings on a regular basis to two colleagues. One of these was his doctoral supervisor (second author) and the other one (third author) was well versed in qualitative research and was familiar with SDT. The role of these two colleagues was to act as "critical friends" and provide a theoretical sounding board to encourage reflection upon, and exploration of, alternative explanations and interpretations as they emerged in relation to the data (e.g., see Smith \& Sparkes, 2006). As part of this dialogic process, (first author) was required to make a defendable case that the available data supported his categorization of themes. This approach should not be confused with more formal procedures to obtain inter-subjective reliability that involves a consensualist conception of truth. Such an approach, according to Kvale (1996) may "lead to a tyranny by the lowest common denominator: That an interpretation is only reliable when it can be followed by everyone, a criterion that could lead to a trivialization of the interpretations” (p. 181). In contrast, the notion of presenting a defendable case acknowledges that while there can be agreement, not all those involved in the process need to define the meanings of a 
particular data set in the same way as they can be positioned differently in relation to their theoretical interests, research experience, and power resources (Krane, Anderson, \& Strean, 1997). This process, therefore, should not be considered a validity or reliability “check” with truth-as-correspondence overtones in (post)positivist, (neo)realist, or what some might call (quasi)foundationalist terms (see Smith and Deemer, 2000; Smith \& Sparkes, in-press a). Rather, the different perspectives offered by critical friends are used as a resource for challenging and developing the interpretations made by any one researcher as they construct a coherent and theoretically sound argument to defend the case they are making in relation to the data generated in a particular study (see Smith and Deemer, 2000). As such, despite disagreements, a case can be seen as defendable and the interpretation offered can be accepted as plausible. Importantly, this acceptance acknowledges that other plausible interpretations of the data can exist that are also defendable but are not being utilized in a particular study.

\section{Results and Qualitative Analysis}

\section{The Emphasis on Student Assessment}

Many of the teachers indicated that an emphasis on student assessment, common in Western cultures, influenced how they motivate their students. Simon is a 25 year-old who had taught PE for three and a half years at a school that received extra funding to specialize in sport. Following a question about the potential existence of pressures from the school system, Simon explained how the emphasis on student assessment may make him control and coerce his students:

Everything is exam focused because you're striving to get the best results from the students, and it's important for them because obviously it's their GCSE's (General Certificate of Secondary Education). It's the last time they have to do an exam in school, so it's very important for them and you're under a lot of 
pressure to help those students perform and if not help, force those students to perform because they need something so they can actually get anywhere in life.

Similarly, Hayley, a PE teacher with 25 years experience, highlighted the increased emphasis on student assessment compared to when she first began teaching. Also, she indicates that she would prefer to give students more practice time to enhance their competence, rather than assessing them:

Hayley: Now that PE, like any other subject, has got to have an assessment at the end of it, you've got to give them a level. Whereas, I wasn't brought up into teaching where you gave them a level or a grade, but it was always "your son is an excellent sportsman”.

Interviewer: Has that affected the way you teach in any way?

Hayley: They've got to put it into a routine and they've got to show me this and I'm rushing it through. Whereas, I think some kids would have benefited a damn sight better from me taking my time and just getting them to achieve something that they could achieve, keep practicing it. They’ve lost out on practice time because they're expected to bung that in that routine, show miss, “yes that was brilliant”, so I’ve found that a bit limiting and restricting.

This conflict between an assessment-based culture and the teachers’ wishes regarding how they would like to teach was also mentioned by Joe, a 27 year-old colleague of Simon's: “I don't want to use 'come on, this is all for your grades', because obviously PE is more than that, but that is a motivating factor at the end of the day”. Joe assumes that emphasizing grades will motivate students, but other reasons to participate in PE exist. Indeed, SDT argues that if short-term participation is taken as the primary indicator, emphasizing grades may successfully energize students during boring activities. Nonetheless, the detrimental 
cognitive, affective and behavioral consequences of promoting an external focus (i.e. obtaining a grade) over a longer period of time must be considered, particularly with initially self-determined students (Deci et al., 2001).

Joe and Hayley use motivational strategies that conflict with their teaching beliefs, as wells as contradicting empirical suggestions. Indeed, Hayley provides an interesting parallel between SDT and her experiences by indicating that the "limiting and restricting" teaching context detrimentally influences her behaviors towards students. This implies that the contemporary teaching context pressures these teachers to teach in ways that they do not value, which may have detrimental effects on the teachers' own motivation (Taylor et al., 2008). Consequently, the emphasis on student assessment may influence teachers to create a motivational climate that is debilitative to students' motivation.

The teachers' own performance evaluations

In addition to the possible pressures that arise from the emphasis on student assessment, the teachers also highlighted that pressure comes from their own performance evaluations by the school. These evaluations often promoted empirically maladaptive motivational strategies. For example, Carl, a 25 year-old teacher in a school founded on Catholic beliefs highlighted that he does not support students' autonomy when being evaluated compared to his normal teaching:

Carl: I felt a bit more pressure this year because obviously as a newlyqualified teacher you get so many observations done by the deputy head. Interviewer: Does this affect the way you teach? Carl: I think it makes it more intense. You want to make sure that you get everything right.

Interviewer: What do you mean by intense? 
Carl: If children aren’t doing exactly what you want, you've got a shorter fuse because it needs to be right. You need to be spot on when the inspectors come. So, as a teacher your patience is not as good. Now I'd also say that you, as a teacher, you go back to doing safe activities. I’d almost say more basic drills, more simple things that you know work, rather than perhaps taking a leap of faith and giving the children more freedom. So you probably reduce the freedom of the children because of the pressure. Because if you give children freedom, yes they might respond and you hope that they do, but they don't always, some do abuse it. And so I think with the pressure of OFSTED (Office for Standards in Education; the official body for inspecting schools) you're less inclined to give children freedom and choice.

Similarly, Emma, a 27 year-old teacher in a state-funded school also indicated a shift in her teaching style when she is being evaluated:

Interviewer: You mentioned that if you were being watched and evaluated, it might make you more regimented and more planned. Are there any other ways that it affects the way you teach?

Emma: It probably affects my social interaction with the students. I might not have a laugh with them if I knew I was being watched, just in case. I don't know why really, maybe I'm worried that they might think it’s inappropriate. Well, not inappropriate, just not required.

According to Pelletier et al. (2002), the pressure from being evaluated may have a negative impact on teachers' motivation towards teaching. While this may be the case for Carl and Emma, who highlighted tension and worry as embodied feelings during the evaluation process, an interesting comparison arose during interviews with trainee teachers who viewed the constant evaluations as a necessary and accepted part of training. Hence, the 
negative implications of being evaluated may not arise in this unique sample. Austin, a 23 year-old trainee teacher explained:

Austin: I (feel) the pressure certainly at the moment because I'm training from the people that are observing me. I'm very conscientious in my teaching and try to be very thorough in my planning because I'm seeking to teach at the moment in a way that is best practice rather than ( 2 second pause). The danger is when you're qualified to get into bad habits and to do the lazy thing, whereas, there’s no room for that because I am being observed. Interviewer: Right OK, and what are your thoughts about that pressure then?

Austin: I think it’s healthy, I respond to it. It keeps me on track and means that I'm not lazy in my teaching.

Teacher evaluations are a necessary part of any teaching context. It is encouraging to see that trainee teachers may not feel undue negative pressure from being evaluated; yet, the above excerpts also show how the evaluation of qualified teachers may promote negative feelings and stifle their use of adaptive motivational teaching strategies. This implies that when qualified teachers are being assessed, an emphasis should be placed on further training, as opposed to an emphasis on school ratings from inspectors (as highlighted by Carl). By doing so, teachers may be more likely to perceive the feedback gained from evaluation as competence enhancing rather than controlling, thus facilitating adaptive motivation (Deci et al., 2001). Moreover, this change of emphasis may satisfy teachers' need for autonomy by helping qualified teachers to value the evaluation process and enhance their experiences of teaching.

\section{Conforming to Other Teachers' Methods}

According to Pelletier et al. (2002), teachers' experience pressure to conform to their colleagues' teaching methods, yet only Gary, an Australian teacher now working in southern 
England, indicated this. Unlike Pelletier et al's findings, Gary perceived this pressure to be a positive factor in his teaching:

Interviewer: Do you feel any pressure from any sources when thinking about how you're going to teach?

Gary: There's a lot more pressure on having very similar lesson plans to a lot of other teachers. Like now they're trying to bring over the four phase lesson, whereas, PE has been doing that for a long time. So there is pressure from other parts on how you are supposed to teach.

Interviewer: So what are your thoughts on this pressure?

Gary: I think it's a good thing. I mean they're just trying to get everyone to be more consistent, which is a must.

Gary's positive perception of the pressure to conform is in contrast to previous research and underscores the importance of exploring individuals’ unique embodied experiences. For example, Burk and Fry (1997) highlighted the conflict between a female, first year teacher's beliefs concerning the degree of autonomy she should give to students and the pressure to conform to teacher-oriented, controlling teaching styles. SDT posits that if an individual perceives the functional significance of an event as informational (i.e. noncontrolling and competence enhancing), as in Gary's case, then the event will be adaptive to the individual's self-determination (Deci \& Ryan, 1987). According to Deci and Ryan’s theorizing, another teacher could plausibly perceive the pressure to conform as controlling, and thus maladaptive. This implies that school-level interventions that encourage teachers to conform to recommended teaching methods remain dependent on the teachers' individual perceptions. Thus, when attempting to change PE teachers' motivational strategies, it may be fruitful to target the individual teacher in combination with school- or curriculum-level intervention. 


\section{Cultural Norms of the Teacher-Student Relationship}

Reeve (2002) indicated that Western educational cultures are based on teachercentered, controlling approaches. This is consonant with many of the teachers' opinions in the present study that there is a need for a pronounced difference in power and authority in the teacher-student relationship. Carl exemplified this when asked about his opinions on supporting students' autonomy:

Just the practicalities. I'm not sure whether it's always best in front of the children to ask “what do you want to do?” or “what did you think of that?”, because often for a lot of children it has got to be constructive. And I also think that a teacher has to have authority over what the children do and you don't want the children, you know, a bit of anarchy.

In contrast to Carl's beliefs, more experienced teachers indicated discontent with the modern teaching culture. Hayley provided an example, when asked about her opinions on interacting informally with students:

In PE you've got to be able to have a laugh, but you've got to be so careful what you say that I won’t have a laugh. In the old days a kid who'd dropped a ball, I'd say “come on give us the seals” (Hayley imitates a seal) and they would laugh and say “oh shut up!” Now I'd be had up in the courts I think if I said that. So I'm very careful now what I do. I do think it has changed quite a lot. You do have to be a lot more official and a lot more formal.

Hayley indicated that earlier in her career she taught in a manner which emphasized humorous social interaction which was consonant with her beliefs. However, over time a conflict has occurred between how she actually teaches and how she wants to teach. In comparison, two newly qualified female teachers did not share Hayley’s feelings about the importance of social interaction. For example, Karen, a 22 year-old colleague of Carl' 
discusses how she is not very comfortable socially interacting with her students and doesn't think it is important, particularly with younger students:

Interviewer: What do you think of promoting social interaction between the student and teacher in the lessons?

Karen: A fine line again. I think you're always going to have different relationships with every class. I personally find it easier; I come across more myself with the older kids. I keep calling them kids, I'm not meant to. Pupils. I'd get slated if my tutor was listening. Social interaction. A fine line. Interviewer: What do you mean fine line? Karen: You don't want to be over friendly with them. Or I personally don’t want to be over friendly with them. You always want to keep a little bit of yourself back I think. You don't want them to see the real you, the whole you. Interviewer: Why do you think you should keep a little bit back? Karen: Well it's a job, it's the act at the end of the day. You're your own person as well. I don't want them to know, do you know what I mean? I've got a private life as well. I don’t want them to know what I was getting up to at the weekend or last night. Interviewer: So how important is that then regarding their motivation? Karen: I wouldn’t say it has that much importance.

The excerpts of Karen and Hayley provide an interesting contrast in teaching beliefs and further emphasize the need to consider the individual teacher when exploring teaching contexts. The above passages also emphasize how the younger teachers seem to perceive the importance of satisfying students’ psychological need for relatedness via a close teacherstudent relationship very differently compared to the more experienced teachers interviewed. 
Another example of how the teacher-student relationship may have changed over time seems to benefit students by stopping verbal abuse by teachers. Bruce, a 44 year-old teacher in a state-funded school provided an example:

The school system has changed. It has altered the way PE teachers approach (teaching). There are a certain amount of PE teachers who are bully boys; they bullied you in to doing stuff. One of my PE teachers was a bit of a bully in some ways, not physically but verbally. So I think obviously the system has changed. You can’t be verbally abusive to pupils or you can’t be physically abusive to them either, whereas, in the past you have been able to.

It appears that the cultural norms of the teacher-student relationship can both promote and inhibit adaptive motivational climates. From Bruce's perspective, they inhibit the use of bullying; but on the other hand, Hayley believes it de-emphasizes social interaction between teachers and students. The picture is further distorted by cultural norms impacting upon individual teachers differently. For example, the diminished emphasis on social interaction with students provides conflict for Hayley but is embraced by Karen. This implies that the exploration of how the culture affects individual teachers' lived experiences should not be sacrificed to pursue questions that deal with how cultural norms impact upon teachers in general. Rather, both research avenues will provide us with different, but equally important information.

\section{Time Constraints}

Teachers in the present study highlighted that perceived time constraints were a consistent barrier to promoting adaptive motivational climates. As Simon succinctly puts it, "there's just not enough time ever to get everything in and get all the kids to understand it". This neglect of students who may take more time to understand tasks is in line with Ames' (1992) concept of an ego-oriented climate that emphasizes normative comparison and 
exacerbates differences in ability levels. Specifically, Ames suggests that not allowing lower ability students the necessary time to complete tasks will undermine their perceived competence. Gary also indicated that the lack of time in PE lessons compelled him to create such a damaging motivational climate:

Sometimes if you've only got a short period of time to do a particular topic you do have to start pushing through things, but I'd like to keep going until the students actually get what we're doing in class.

As well as encouraging ego-oriented motivational climates, the lack of time also prevented the support of students' autonomy, as Bruce described:

I think if you've got a short lesson of time to do something in, you've got less flexibility in how you approach it. You want to get the core material dealt with. If you've got half an hour to do it in, then I'm sorry, I'm not interested in what you've (the students) got to say, you're getting on with the activity. Similarly, Carl explained that he would give more autonomy to students if lessons were longer:

I would probably say that if we had two hour lessons, double lessons instead of an hour single lesson, you'll have more opportunity to give a bit of choice and autonomy. But it’s limited how much you can do in twenty five minutes because you have to get them doing, get them going quickly.

As shown above, many teachers mentioned that they wish more time was allocated to PE lessons. However, rather than indicating that they wanted more hours in the week dedicated to PE, they indicated that the length of each lesson was a problem. Most lessons cited by the teachers were approximately an hour in length, however, as Patricia, a 25 yearold newly qualified teacher explains: 
At the last school I was at, once the pupils have got changed and you'd have to allow time for them to get dressed again you're left with maybe half an hour, twenty minutes to do a lesson, which is no time at all.

In this sample, time constraints may provide the biggest conflict between how teachers have to teach and how they would like to teach, as well as contradicting empirically suggested strategies. Educational authorities need to consider the possibility of extending the time available for PE lessons or allocating “double” lessons for PE. This may help the teachers to fit in all objectives of the lesson without compromising their use of adaptive motivational strategies.

\section{The Teachers' Perception of the Students}

In addition to demands from school authorities and the time constraints of PE lessons, teachers highlighted that they behaved differently depending on the students. For example, Simon indicated that he behaves differently depending on the students' general motivation at school (i.e., not just their motivation in PE):

Students who are highly motivated with school, the chances are that you're going to be able to develop relationships with them quicker and friendships with them quicker so they'll be responding to you better. Whereas, the group who don't have a good opinion of school, good motivation for school, takes longer to develop that relationship and so you may well treat the groups differently.

Simon also shows the importance of considering teachers’ psychological need for relatedness, in addition to the psychological needs of the students. By perceiving a sense of connectedness with motivated students, Simon is more likely to feel positive about those relationships, hence, altering his behavior towards motivated students. 
In addition, many teachers mentioned that their choice of strategy depends on the students’ motivation specifically towards PE. Previous research (e.g., Pelletier et al., 2002; Taylor \& Ntoumanis, 2007) has similarly found that teacher perceptions of student motivation were related to the degree of autonomy support they provided. This influence is exemplified by Carl:

Interviewer: Can you give me an example when you have changed your teaching?

Carl: If children are extremely motivated for PE, then you try and give them a bit more responsibility, because they're willing to take it on and to help the lesson. Those people who aren’t well motivated you try, what would you try and do? If they're not that well motivated to the extent that they don’t bring their kit or anything you have to let them know it's not acceptable for them not to bring their kit.

Teachers' reactions toward poorly motivated students are not always the most appropriate as shown by experimental and PE-based research indicating that teachers prefer working with students who are intrinsically motivated, or show high levels of effort (Biddle \& Goudas, 1997; Pelletier \& Vallerand, 1996). Steven, a director of PE and sport at a privately-funded school similarly indicated that he withdraws psychological resources when students show little effort: "If we've got to year twelve and that boy who couldn't swim in year seven still can’t swim, and doesn't try, I've done with him”. Relatedly, Rachel, a 22 year-old, newly qualified PE teacher highlights poor student discipline as a potential reason to withdraw teaching support. In response to being asked whether her students influence her teaching, Rachel stated:

Some kids will come in and they can be really obnoxious with you, and they keep going and going and it gets to the point where you just think bugger 
them, not dealing with this anymore. "You, just go away", and dismiss them which is completely the wrong. But if you kept going you'd end up blowing your lid. So you just ignore them for a while and I suppose maybe neglect them for a while.

It is very worrying that Steven \& Rachel may withdraw time and effort from students who need the greatest attention. A withdrawal of personal resources may lead to diminished motivation in students (e.g., Taylor \& Ntoumanis, 2007), which, in turn has been found to be associated with poor discipline in PE (Spray \& Wang, 2001). Consequently, these strategies may exacerbate the students' poor discipline over time. Similarly, Carl and Steven’s examples above show how the teachers may also magnify students' levels of selfdetermination over time via their chosen motivational strategies. This is fine for highly selfdetermined students, who may be more likely to receive adaptive motivational strategies. Yet students with low-self-determination may receive maladaptive motivational strategies from the teacher which, in turn, may further reduce their self-determined motivation. Interestingly, and contrary to what one might expect, Carly indicated that she gave poorly behaved students more responsibility:

They (poorly disciplined students) just lack concentration and we tend to give them responsibility, be a coach, be in charge of their group, and that tends to then increase their motivation. They want to take part because they're being the coach, acting as the teacher that kind of thing.

Despite Carly being in the minority, it is encouraging that not all teachers use maladaptive strategies towards poorly disciplined or poorly motivated students.

In addition to student motivation and discipline, some teachers in the present study said that they change their teaching strategies, depending on their perceptions of student ability in PE. This dimension corroborates research evidence which suggests that teacher 
perceptions of students' ability, influences the ways in which they interact with the students in PE (Martinek \& Karper, 1986). For example Gary explained:

I mean you give the higher ability students a task and you can let them go off and do it and they'll be quite fine. Where I could spend more time with low ability students and just try and get their motivation up that way.

While this indicates that these teachers may be aware of the need for extra teaching effort with low ability pupils, this extra effort may be partly undermined because some of the strategies mentioned by the teachers have been shown to be maladaptive to students' motivation. For instance, SDT argues against the use of external rewards to motivate students (Deci et al., 2001). Despite this, Rachel highlighted another way she changes her teaching depending on the students:

If they're low ability, they're usually low ability because of the lack of interest.

The lack of interest will be because of a lack of motivation, not really wanting to be there sometimes. The strategies do sometimes change to how you get them through it. Sometimes you might have to bribe them to get them to do something.

In summary, teachers' perceptions of the students seem to play a major role in their choice of motivational strategies. However, teachers' motivational strategies may not be appropriate if these perceptions are inaccurate. Consequently, it may be suitable for teachers to be educated in identifying specific behaviors associated with various motivational states, increasing the likelihood of choosing the appropriate motivational strategy.

\section{The Students’ Physical Characteristics}

As well as the students' psychological characteristics, it seems that some of the teachers in the present study are aware of the need for reducing body image concerns in PE, especially among amotivated students (Ntoumanis, Pensgaard, Martin, \& Pipe, 2004). 
Specifically, in cases where students are overly conscious of their weight or skin ailments, the teachers mentioned that they would acknowledge the students negative feeling more. For example, Tim, head of PE at a state school explained:

It might be that he has got eczema on his legs and he might not like wearing shorts. He likes taking part in sport but he feels intimidated because the kids will laugh. So therefore he doesn't bring kit and doesn't take part. Then he gets grief off the teacher. So (his) motivation (to) take part is decreased. Whereas if he (the teacher) rung his parents up or chatted to him (the student) and got to the root cause and allowed him to wear tracksuit bottoms he can then take part and hopefully his motivation will start to improve.

The teachers in the present study referred only to male students' body concerns. This suggests that despite female body concerns receiving more attention in both the popular and empirical literature (Stice \& Whitenton, 2002), male body concerns are important and need to be investigated.

\section{The Students' Age}

Most of the teachers commented that they taught differently dependent on the students' age. However, the reasons behind these age-related differences in teaching strategies varied greatly. Some teachers mentioned that, because contextual motivation and concentration is high in younger age groups, they use different strategies compared to strategies that they use with older students. For example, Patricia perceived that older students lack concentration, and hence she deemed that more emphasis on enjoyment was necessary:

The strategies I use to keep them motivated would change. I'm trying to think of an example. For a year ten group or a year eleven group (14-16 year-olds), I probably find I have to base the lessons around games or if it's a PE theory, 
make it more practical just to keep them going all the time, rather than sitting there and just filling in worksheets or listening to me. It has to be a lot more on the go because they're the ones that tend to be that little bit more boisterous.

In addition, teachers indicated that they use alternative strategies for different age groups depending on their level of maturation. For example:

Interviewer: What do you think of involving the students in the running of PE lessons?

Austin: I think the more that can be done the better, because more learning will occur if they're given greater reign in what they're doing. They're likely to be more (2 second pause). Increasing the feeling of responsibility and involvement will help them to learn and to want to learn in the PE environment. Having said that, it's the sort of skill that requires more maturity and so would be seen increasingly as the child grows through the years. Moreover, it was perceived that the power imbalance between students and teachers changed developmentally, thus altering the amount of autonomy support and interpersonal involvement used. For example, Carly suggested:

Depending on the year group. Lower school you need to have the teacherpupil professional relationship. Yes you've got to communicate with the kids and that's important, but in terms of the social interaction I wouldn't have said it’s particularly important, My sixth form class (sixteen to eighteen year olds) is completely different because they're only five years younger than me, you can have social, you can discuss other things as well at the same time and I'm on first name terms which gives them a greater responsibility when they're in sixth form as well which I think is quite important. 
These extracts indicate that teachers' beliefs about general developmental differences have a strong impact upon the motivational strategies that they use. However, such broad beliefs are more likely to be inaccurate compared to specific beliefs. Consequently, teacher strategies may not be adapted to the needs of individual students; hence, students who do not fit in with their teachers' general developmental beliefs about their age group may suffer motivationally.

\section{The Students' Gender}

In accordance with past literature (e.g., Jones \& Dindia, 2004), some teachers felt that they adapted their attempts to motivate students depending on the students' gender. Specifically, teachers in the present study suggested that boys find competition and social comparison conducive to their motivation. In other words, these teachers use more egoinvolving strategies with boys. Contrastingly, the teachers perceived that girls prefer activities that do not promote normative comparison. An example is provided by Joe:

Interviewer: What do you think motivates students in PE?

Joe: In terms of lads (boys), I think there's a sense of competitiveness and sense of achievement which they really love. So games, competition, it's a big motivating factor. For girls probably less so, probably more potential insecurity issues in terms of PE so try and find ways where they won't be humiliated or won't be shown to be rubbish at something.

Above, Joe provides an example of a classically patriarchic physical education class, where competitiveness is seen as a male standard and females are expected to be passive participants (Satina, Solmon, Cothran, Loftus \& Stocking-Davidson, 1998). According to Satina and colleagues, this is typical of PE classes in Western cultures and often alienates and silences female students. 
As with age, teachers seem to stereotype according to gender. Students who do not fit with their teacher's stereotypes will therefore suffer motivationally. Yet, there is no empirical evidence to suggest that an ego-involved climate is more adaptive to boys than girls. This is another example where the teaching context, in the form of the students, manipulates teachers into utilizing maladaptive strategies.

\section{Discussion}

Using SDT as a theoretical reference, this study extends the current literature by offering an in-depth account of possible social-contextual influences on PE teachers' motivational strategies. SDT was used as the guiding framework in our study because it discusses how the social context can influence one's psychological need satisfaction and behaviors towards others (Gagné, 2003; Taylor et al., 2008). Frequent examples of this proposition arose throughout our qualitative analysis. For example, Simon and Hayley explicitly spoke about the restricting nature of the teaching context and the impact this has on their motivational strategies towards students. Similarly, Carl and Emma indicated that the controlling nature of teaching evaluations has detrimental effects on their own well-being and compels them to use motivational strategies that contradict SDT-based empirical suggestions. In the same way, Simon and Carly altered their motivational strategies depending on the degree to which their relationship with students satisfied their own psychological need for relatedness. Overall, this study found that various aspects of the teaching context served to thwart teachers' need for autonomy, competence and relatedness. Furthermore, these need thwarting environments often resulted in teachers’ using motivational strategies that prevented the satisfaction of students' psychological needs.

Despite the frequent mentioning of adverse contextual influences, teaching evaluations that were perceived to have a detrimental effect on Carl and Emma were perceived to be informational and competence enhancing by Austin. Moreover, Gary also 
perceived the pressure to conform to colleagues' teaching methods to improve his teaching. By integrating SDT with our qualitative methods we were able to explore these distinct and contrasting experiences. In accordance with Deci and Ryan’s (1987) theorizing, these diverse accounts highlight the importance of individuals' unique perception of the functional significance of a context. This also indicates the need to consider the PE teacher as an individual rather than as part of a collective group that is influenced by the teaching context in identical ways.

As well as the impact of the teaching context on the PE teachers, SDT also structured our interpretations of the motivational strategies used by teachers. That is, teaching behaviors that may support or thwart students' innate psychological needs for autonomy, competence, and relatedness were explored. Clearly, studies using different theoretical perspectives will view teachers' strategies from an alternative angle. For example, based on the theoretical tenets of SDT, we interpreted Joe and Rachel's use of external rewards as debilitating to students' self-determination, thus maladaptive to their motivation. Studies incorporating a behaviorist approach to motivation may view these motivational strategies as adaptive (e.g., Eisenberger \& Cameron, 1996). Further, different contextual determinants may arise from PE teachers' narratives in studies that utilize different theoretical perspectives. As a result, this may be an important avenue for future research.

This study has also highlighted other potential avenues for future research. First, the majority of the sample in the present study was of White ethnicity and worked in statefunded, mixed-gender schools. It may be productive to conduct further investigation with PE teachers from private and single-sex schools, as well as non-White PE teachers. A theme that ran throughout the interview with Steven, a teacher in a private, boys-only school was how little he had to focus on student motivation: “The majority of them (students) don't need motivating. The nature of this school, the nature of the pupils, they are, not everyone, but by 
enlarge, the majority are very well motivated towards their all round education”. Interestingly, despite the relative homogeneity of the sample in terms of ethnicity and type of school, the uniqueness of each case is emphasized throughout the text. This underscores the importance of considering the PE teacher as an individual. Second, this study focused on the teaching context from the perspective of the PE teacher. An interesting contrast to this study may be the examination of the school context from the students' perspective. This type of study may also shed light on specific issues concerning different types of students.

To summarize, this study offers a starting point for examining social-contextual determinants of teacher motivational strategies in PE. The identification of these is important because it allows a greater understanding of the reasons why teachers do not always utilize adaptive teaching strategies. Greater awareness of teachers' embodied experiences, in particular their emotional and behavioral reactions to aspects of the teaching context will help to inform schools and educational bodies of how to aid PE teachers in delivering better quality teaching to all students. 


\section{References}

Ames, C. (1992). Classrooms: Goals, structures, and student motivation. Journal of Educational Psychology, 84, 261-271..

Biddle, S., \& Goudas, M. (1997). Effort is virtuous: Teacher preferences of pupil effort, ability and grading in physical education. Educational Research, 39, 350-355.

Burk, D. I., \& Fry, P. G. (1997). Autonomy for democracy in a primary classroom: A first year teachers’ struggle. Teaching and Teacher Education, 13, 645-658.

Cavill, N., Biddle S., \& Sallis, J. F. (2001). Health enhancing physical activity for young people: Statement of the United Kingdom expert consensus conference. Pediatric Exercise Science, 13, 12-25.

Chase, S. (1995) Taking narrative seriously: Consequences for method and theory in interview studies. In R. Josselson and A. Leiblich (Eds) Interpreting experience: The narrative study of lives (pp. 1-26). Thousand Oaks, CA: Sage.

Deci, E. L. \& Ryan, R. M. (1987). The support of autonomy and the control of behavior. Journal of Personality and Social Psychology, 53, 1024-1037.

Deci, E. L., \& Ryan, R. M. (2000). The "what” and "why” of goal pursuits: Human needs and the self-determination of behavior. Psychological Enquiry, 11, 227-268.

Deci, E. L., Ryan, R. M., \& Koestner, R. (2001). The pervasive negative effects of rewards on intrinsic motivation: Response to Cameron (2001). Review of Educational Research, 71, 43-51.

Deci, E. L., Spiegel, N. H., Ryan, R. M., Koestner, R., \& Kauffman, M. (1982). Effects of Performance Standards on Teaching Styles - Behavior of Controlling Teachers. Journal of Educational Psychology, 74, 852-859.

Eisenberger, R. \& Cameron, J. (1996). Detrimental effects of reward: Reality or myth? American Psychologist, 51, 1153-1166. 
Flink, C., Boggiano, A. K., \& Barrett, M. (1990). Controlling teaching strategies: undermining children's self-determination and performance. Journal of Personality and Social Psychology, 59, 916-924.

Gadamer, H-G. (1975). Truth and method. New York: Seabury Press.

Gagné, M. (2003). The role of autonomy support and autonomy orientation in prosocial behaviour engagement. Motivation and Emotion, 27, 199-223.

Hagger, M. S., Chatzisarantis, N. L. D., Culverhouse, T. \& Biddle, S. J. H. (2003). The processes by which perceived autonomy support in physical education promotes leisure-time physical activity intentions and behavior: A trans-contextual model. Journal of Educational Psychology, 95, 784-795.

Harris, M. J. \& Rosenthal, R. (1985). Mediation of Interpersonal Expectancy Effects - 31 Meta- Analyses. Psychological Bulletin, 97, 363-386.

Jones, S. M., \& Dindia, K. (2004). A meta-analytic perspective on sex equity in the classroom. Review of Educational Research, 74, 443-471.

Krane, V., Anderson, M. B., \& Strean, W. B. (1997). Issues of qualitative research methods and presentation. Journal of Sport and Exercise Psychology, 19, 213-218.

Kvale, S. (1996). Interviews: An introduction to qualitative research interviewing. London: Sage.

Lieblich, A., Tuval-Mashiach, R., \& Zilbar, T. (1998). Narrative research: Reading, analysis, and interpretation. Thousand Oaks: Sage Publications.

Martinek, T., \& Karper, W. (1986). Motor ability and instructional contexts: Effects on teacher expectations and dyadic interactions in elementary physical education classes. Journal of Classroom Interaction, 22, 16-25.

Maykut, P., \& Morehouse, R. (1994). Beginning qualitative research: A philosophic and practical guide. London: The Falmer Press. 
Newby, T. J. (1991). Classroom motivation: Strategies of first-year teachers. Journal of Educational Psychology, 83, 195-200..

Ntoumanis, N., Pensgaard, A. M., Martin, C., \& Pipe, K. (2004). An idiographic analysis of amotivation in compulsory school physical education. Journal of Sport \& Exercise Psychology, 26, 197-214.

Patton, M. Q. (2002). Qualitative evaluation and research methods (3rd Ed.). Thousand Oaks, CA: Sage.

Pelletier, L. G., Seguin-Levesque, C., \& Legault, L. (2002). Pressure from above and pressure from below as determinants of teachers' motivation and teaching behaviors. Journal of Educational Psychology, 94, 186-196.

Pelletier, L. G., \& Vallerand, R. J. (1996). Supervisors' beliefs and subordinates' intrinsic motivation: A behavioral confirmation analysis. Journal of Personality and Social Psychology, 71, 331-340.

Reeve, J. (2002). Self-determination theory applied to educational settings. In E. L. Deci \& R. M. Ryan (Eds.), Handbook of self-determination research (pp. 183-203). Rochester, NY: University of Rochester Press.

Satina, B., Solmon, M. A., Cothran, D. J., Loftus, S. J., \& Stockin-Davidson, K. (1998). Patriarchal consciousness: Middle school students’ and teachers’ perspectives of motivational practices. Sport, Education and Society, 3, 181-200.

Smith, J., \& Deemer, D. (2000). The problem of criteria in the age of relativism. In N. Denzin \& Y. Lincoln (Eds.), Handbook of qualitative research ( $2^{\text {nd }}$ Edition). Thousand Oaks, CA: Sage.

Smith, B. \& Sparkes, A. C. (2006). Narrative inquiry in psychology: Exploring the tensions within. Qualitative Research in Psychology, 3, 169-192.

Smith, B. \& Sparkes, A. C. (in-press a). Narrative inquiry in sport and exercise psychology: 
What is it, and why might we do it? Psychology of Sport and Exercise.

Smith, B. \& Sparkes, A. C. (in-press b). Narrative analysis and sport and exercise psychology: Understanding stories in diverse ways. Psychology of Sport and Exercise.

Sparkes, A. C. (1992). The paradigms debate: An extended review and a celbration of difference. In A. C. Sparkes (Ed.), Research in physical education and sport: Exploring alternative visions (pp. 9-49). London: Falmer Press.

Sparkes, A. C., Templin, T. J., \& Schempp, P. G. (1990). The problematic nature of a career in a marginal subject: some implications for teacher education programmes. Journal of Education for Teaching, 16, 3-28.

Spray, C. M., \& Wang, C. K. J. (2001). Goal orientations, self-determination and pupils’ discipline in physical education. Journal of Sports Sciences, 19, 903-913.

Stice, E., \& Whitenton, K. (2002). Risk factors for body dissatisfaction in adolescent girls: A longitudinal investigation. Developmental Psychology, 38, 669-678.

Taylor, I. M., \& Ntoumanis, N. (2007). Teacher motivational strategies and student selfdetermination in physical education. Journal of Educational Psychology, 99, 747760.

Taylor, I. M., Ntoumanis, N, \& Standage, M. (2008). A self-determination theory approach to understanding antecedents of teachers' motivational strategies in physical education. Journal of Sport and Exercise Psychology, 30, 75-94. 
THE SOCIAL CONTEXT AS 33 